Post-print article information:

To cite the author's post-print version:

Sabri Y., Zarei, M. H. and Harland, C. (2019) "Using collaborative research methodologies in humanitarian supply chains", Journal of Humanitarian Logistics and Supply Chain Management, in press.

\title{
Using collaborative research methodologies in humanitarian supply chains
}

\begin{abstract}
Purpose- The purpose of this article is to develop an existing collaborative research methodology process (Sabri, 2018), contextualise it for application in humanitarian supply chains and test it empirically.
\end{abstract}

Design/Methodology- Building on collaborative research methodology and humanitarian supply chain literatures, the Sabri (2018) collaborative research methodology process is further developed to comprise eight phases of collaborative research contextualised for the humanitarian supply chain domain. The process is applied in a collaborative research case of academia-practitioner knowledge co-creation in a humanitarian supply chain setting, focusing on environmental sustainability improvement. The collaborative case analysis suggests a number of refinements to the elements of the process. Two cycles of academia-practitioner collaborative research were undertaken.

Findings- In testing the process, a noticeable improvement in the collaboration among different humanitarian stakeholders was observed, leading to improved stakeholder management. The implementation improved the sustainability awareness and social inclusion of the affected population. Rurality, remoteness, security issues, and resistance of field staff against change were among the main challenges for supply chain researchers to engage in collaborative research in the humanitarian domain.

Originality/value -The article addresses the rigour-relevance-reflectiveness debate in the humanitarian supply chain domain. A collaborative research methodology process derived from action research is further developed using humanitarian literature, then applied in a humanitarian logistics case focused on environmental sustainability. The collaborative research methods process facilitates engaged scholarship among the humanitarian stakeholders, as the researchers' roles move from observatory to participatory knowledge broker. 
Keywords Humanitarian supply chain, humanitarian logistics, collaborative research, action research, sustainability.

\section{Introduction}

The need for better coordination and collaboration in humanitarian supply chains is acute; this is primarily due to the high uncertainty at the demand and supply sides (Van Wassenhove, 2006), The need for risk mitigation in humanitarian supply chains because of this uncertainty has been emphasised (Ben-Tal et al. 2011). However, the particularities of these uncertainties make coordination and collaboration in humanitarian supply chains different to that in traditional, non-humanitarian settings (Gatignon et al. 2010). Therefore more research on how to improve coordination and collaboration in humanitarian supply chains is required.

Despite recognition of the need for more research, concerns have been expressed about the limitations of ongoing research in humanitarian supply chains because of the proliferation of use of particular research methodologies. In the humanitarian supply chain domain, simulations, modelling and qualitative case studies are dominant methodologies (Kunz and Reiner, 2012). However, their appropriateness for addressing multidimensional challenges of this complex, uncertain environment has been the subject of debate (Näslund, 2002; Näslund et al., 2010). Using the same, limited range of research methodologies can lead to 'produce[ing] similar questions and answers' (Gammelgaard, 2004; p.479). The same notion is expressed in Näslund (2002; p. 327).

"If researchers within a certain academic discipline do the same kind of research as everyone else within the discipline, then how useful will that research be?"

There might be usefulness in this kind of research, albeit 'not useful enough' (Gammelgaard, 2004; p.483). The intent behind this research is not to undermine or replace other research methodologies, as all types of research are needed (Näslund, 2002) since they reflect how logistics and supply chain researchers view reality from different perspectives (Gammelgaard, 2004). However, knowledge of humanitarian supply chains cannot grow and achieve the hopes it holds, for its researchers and practititioners, if it continues to create that knowledge using the same methodologies (Näslund et al., 2010). A further concern with humanitarian supply chain research is the rigour-relevance gap (Bartell et al., 2006; Jahre et al., 2015; Kunz et al. 2017; Sohn, 2018). This has increased interest in the use of research methods that might help close this gap. Collaborative 
research methods in humanitarian settings involve research collaborations between academics and practitioners, practitioners and affected populations, academics and affected populations, and academics, practitioners and affected populations. To enable the creation of practically relevant and theoretically based knowledge, frameworks and models, research in humanitarian settings would benefit from a proactive approach of academia-practitioner collaboration to research across university, institutional and organisational boundaries (Bartell et al., 2006; Prasad et al., 2017). As such, collaborative research methodologies with their participatory focus, bridge two worlds; academic concepts and practitioners operating models (Chang et al. (2010), and create contextually relevant knowledge (Sohn, 2018). Engaged scholarship is “... a collaborative form of inquiry in which academics and practitioners leverage their different perspectives and competencies to coproduce knowledge about a complex problem or phenomenon that exists under conditions of uncertainty found in the world." (Van de Ven and Johnson, 2007; p.803) and therefore it appears to be a very relevant research methodology for humanitarian supply chain research.

In the present research we use an existing collaborative research process (Sabri, 2018) and contextualise it to apply it to a humanitarian logistics problem. The collborative research methodology process presened here is based on similar earlier processes from the supply chain and operations management domain (see e.g., Coughlan and Coghlan, 2002; Näslund et al., 2010). Moreover, we incorporate learning from the collaborative humanitarian field expereinece reported in prior literature (see e.g., Chandes and Pache, 2010; Jahre et al., 2012; Pedraza-Martinez et al., 2013; Jahre et al., 2015; Prasad et al., 2017). Through analysis of 17 collaborative research projects in the broader humanitarian setting, themes from these are used in the contextualisation of the methodology process. To test the developed process, we apply it in a humanitarian logistics case study relating to environmental detriment caused by packaging in humanitarian supply chains. Environmental sustainability has not been sufficiently addressed in humanitarian supply chains in practice; Eng-Larsson and Vega (2011), Sarkis, Spens et al. (2012), Haavisto and Kovács (2014), Abrahams (2014), and Kunz and Gold (2017) all call for more research on this topic in humanitarian logistics research, highlighting that as humanitarian operations increase globally, so does the environmental burden they cause. The attention of scholars in the humanitarian arena has largely been, to date, directed to disaster relief, focusing on improving preparedness and response (Leiras et al., 2014). The urgency of 
humanitarian response to disasters may be perceived as outweighing the need for sustainability (Cravioto et al. 2011).

We apply the developed process in a single case with two cycles of collaborative research between academic and practitioner partners in a humanitarian supply chain setting. After the case analysis, we refine elements of the process and provide insights on lessons learnt from the research.

The contributions of the present research are threefold. First, to the best of our knowledge, this study is novel in providing a comprehensive process for collaborative research in humanitarian supply chain settings. Second, we provide empirical findings on how collaboration between academics and practitioners helped to improve sustainability of the management of packaging in humanitarian logistics supply chains. Third, we identify the implications, benefits and challenges of engaging humanitarian supply chain researchers and practitioners together in a collaborative research project. In so doing, the outreach of humanitarian logistics research is increased (Kovács, 2012), and decisions in humanitarian crises can be based on appropriate evidence (Pedraza-Martinez et al., 2013; Sandvik and Lemaitre, 2013).

The article is organised as follows. First, we examine collaborative research in section 2. Next, section 3 discusses collaborative research in humanitarian supply chains and proposes a collaborative research process. The application of the process to a humanitarian case is shown in section 4 . Then, the findings and refinements to the process are discussed in section 5. Finally, section 6 concludes the article and summarizes theoretical and practical contributions.

\section{Collaborative research methodologies}

Basing practice decisions on research evidence has a long history in the fields of law, medicine and public policy, entering the field of management more recently (Pfeffer and Sutton 2006). The process of evidence-based decision making involves formulation of the research question, gathering appropriate research findings and evidence, assessing the validity, quality and appropriateness of the evidence to the problem in hand, presenting the evidence in a way that is useful to the decision-making process, then, applying it to that decision-making process (Gray 2004, Kovner and Rundall 2006). There are various approaches to evidence-based management that follow similar processes from problem identification to decision and evaluation (Robbins 2008). Engaged scholarship emerged 
as a way to enable co-creation of knowledge, and to facilitate the engagement and integration between members of the academic and practice-based research team (McLean et al., 2002; Van de ven and Johnson, 2007). For management research to be termed collaborative, two parties or more need to be involved in the knowledge co-creation process, of whom at least one is a practitioner (Pasmore et al., 2008). This type of collaborative management research is positioned close to the Scandinavian tradition of interactive research (see e.g. Ellström, 2007; Svensson et al., 2007). Co-creation of knowledge entails having shared objectives, jointly deciding on the research purpose and mutually framing the research questions. It may also require co-designing of action plans and co-evaluation of the project outcomes (Shani et al., 2012).

\section{Types of collaborative research methodologies}

Shani et al. (2004) identify eight types of collaborative research methodology; action science, appreciative inquiry, clinical inquiry, developmental action inquiry, intervention research, participatory inquiry, table tennis research and action research. Collectively, they are concerned with action, intervention and transformation that leads to theory building and knowledge co-creation. Some of the outlined eight types are viewed by other scholars as a participatory approach to inquiry and the research process; Bradbury (2013, p.3) questioned whether action research is a methodology of its own:

"Action Research is not a method, but an orientation to inquiry, with many schools, theories and practices".

Hence, it could be applied in the settings of a case study (see e.g. McManners, 2016).

\section{Collaborative research in humanitarian supply chains}

The application of collaborative research methodologies in humanitarian supply chain research has been very limited. In some instances, when adopted, researchers have not explicitly reported using a collaborative research methodology, such as Tomasini et al. (2009), where it is evident that collaboration methodologies and coordination schemes can significantly reduce costs and enhance the preparedness and response of humanitarian supply chains. In other cases, researchers specifically identify use of a type of collaborative research; in Appendix 1 we present 17 collaborative research projects in the humanitarian domain. In Chandes and Paché's (2010) study the research team used observant participatory action research as a methodology; one of the team members was embedded (employed) in the practitioner environment. Jahre et al.'s (2012) study used 
action research with more than 50 interviews and 27 site visits. Rigour was ensured by cross-referencing data from multiple sources and having two researchers conduct the interviews and site visits swapping roles between participatory and observatory researcher. In Pedraza-Martinez et al., (2013) participatory research was used to coidentify the research problem, develop optimisation models for vehicle routing and fleet management in the humanitarian field and implement these in humanitarian organisations. Jahre et al.'s (2015) empirical study ensured research rigour through triangulation of multiple methods for data collection and analysis and using multiple researchers with different roles. The research project had cycles of interventions and the research team, including humanitarian practitioners, had reflective sessions to discuss data analysis and needed intervention.

Collaborative research in humanitarian settings has involved collaborations between combinations of academics, practitioners and affected populations. The focus of this article is on academic-practitioner collaboration. Sandvik and Lemaitre (2013) used a case-study design combining traditional methods of legal analysis, ethnographic observation, and participation amongst university researchers and a research committee set up by an NGO. Refstie and Brun (2011) used co-identification of a research problem and co-analysis by academics and practitioners in focus groups. Chang et al. (2010) used multiple rounds of action research intervention with reflective sessions involving researchers and practitioners. Prasad et al. (2017) used a mixed-method approach between action research and non-linear integer programming-based simulation, with a team of researchers and officers of an NGO. From these studies, evidence of the following challenges are summarised in Table 1.

\section{Please Insert Table 1. Challenges of collaborative research in humanitarian settings}

Despite these challenges, many benefits of collaborative research in humanitarian settings are reported, summarised in Table 2.

Please Insert Table 2. Benefits of academic-practitioner collaborative research in humanitarian settings

\section{A process for collaborative research in humanitarian supply chains}


Collaborative research processes are cyclical, and the outcomes are co-evaluated on multiple iterations through phases of: planning, intervention, taking action, and reflectiveness, which can lead to transformation (Canterino et al., 2016). A collaborative research methodology should contribute to theory building of the supply chain domain (Coughlan and Coghlan, 2002) through high level involvement of both researchers and practitioners (Schein, 2006).

Prior research has provided various collaborative research methodology processes based on action research in the supply chain and operations management domain (Coughlan and Coghlan, 2002; Näslund et al., 2010; Sabri, 2018), as well as the rich humanitarian field experience reported in a number of collaborative research projects, (see e.g., Chandes and Pache, 2010; Jahre et al., 2012; Pedraza-Martinez et al., 2013; Jahre et al., 2015; Prasad et al., 2017, and Appendix 1). Here we combine learning from both these domains to develop a collaborative research process oriented to research in humanitarian supply chain settings. This process is based on the phases proposed by Sabri (2018) and expands elements specifically for the humanitarian logistics context.

In line with other collaborative research methods processes, ours starts by forming a collaborative team, understanding the research problem's context and purpose then proceeds to data collection, practitioners' orientation, collaborative data analysis, joint planning for action, implementation and evaluation and ongoing monitoring.

\section{Please insert Table 3. Collaborative research process for humanitarian supply chain research}

\section{A Collaborative Research Case - Sustainable Humanitarian Supply Chains}

\subsection{Context}

This case is on research and practice of environmental sustainability of humanitarian supply chains. Environmental sustainability has not been sufficiently addressed in humanitarian supply chains; see, for example, Eng-Larsson and Vega (2011), Sarkis, Spens et al. (2012), Haavisto and Kovács (2014), Abrahams (2014), and Kunz and Gold (2017). Because of the increasing scale of global humanitarian operations and the urgency of humanitarian logistics, an increasing environmental burden is occurring, such as the consequential cholera outbreak in Haiti (Cravioto et al. 2011). Green practices may not simply be transferred from commercial sustainable supply chain management and applied to humanitarian logistics due to the fundamental differences between these settings. Such 
differences make it imperative to collaborate with humanitarian practitioners to develop contextualized green practices that fit the specificities of humanitarian logistics. Hence, the researchers were driven by the following research question:

"How can researchers and humanitarian practitioners collaborate to improve the environmental sustainability of humanitarian logistics, considering the specificities of humanitarian context?"

\subsection{Methodology}

Overview

This case applies the phases in our collaborative research methodology process. It is focused on collaborative research between an academic partner and a large international humanitarian organisation (HO). The HO is headquartered in a developed country with many regional and national delegations around the world. Its purpose it to help populations affected by natural disasters and armed conflicts by providing food and shelter. This collaborative research focuses on improving environmental sustainability of the HO's operations in its supply chains.

While embedding environmental sustainability into humanitarian logistics was the main area of investigation of mutual interest, managing packaging waste was chosen as an initial area of focus because of growing concerns in the HO regarding the amount of waste generated by their operations and the way it was disposed. Concern was growing especially in developing countries and crisis-impacted regions with limited resources for recycling and waste management. In the same line, the criticality of packaging in the humanitarian supply chain has been highlighted by previous research (Sohrabpour, Hellström et al. 2012, Regattieri, Gamberi et al. 2018), exemplified by past adverse consequences in the field. For example, empty water bottles were left in the environment after consumption by beneficiaries in Afghanistan (Haavisto and Goentzel 2015) and large-scale disposal of ready-to-eat meals in hard plastic containers delivered to Haiti caused environmental problems (Sarkis, Spens et al. 2012).

The collaboration for this research lasted 19 months during which two collaborative research cycles were completed. The first cycle was completed in nine months and identified unsustainable operations, focusing a pilot study on one area with the highest perceived environmental impact. The second cycle spanned 10 months, evaluating outcomes of the first cycle, and improving the implementation of the pilot. 
Three large humanitarian organisations were targeted as potential research partners with an assumption that larger scale operations may give rise to greater environmental impact. Only one was willing to engage in collaborative research. From the HO side, they wanted information on the background of the researchers and their previous projects with other organisations. The research team was comprised of two researchers with backgrounds in supply chain management and engineering with specific expertise in humanitarian logistics and environmental sustainability. The practitioner team consisted of three members: the chief logistics manager, the logistics coordinator of Africa (the region with the highest environmental concerns), and the environmental and sustainable development advisor. The collaborative research method (CRM) team was therefore a hybrid community of inter-disciplinary researchers and expert individuals from the HO.

\section{Understanding the problem and context}

A memorandum of agreement was signed specifying the goal, scope and responsibilities of each party, confidentiality of data, the expected duration and deliverables of the project. Based on that, the main responsibilities of the practitioner team were providing access for the researchers to organizational data, operations sites, providing detailed feedback on the recommendations of the researchers, and the implementation of approved action steps in the field. A CRM-based methodology was selected and upon the confirmation of the analysis, the researchers conducted a review on green disposal methods for packaging within a two-month period.

\section{Data collection}

In the first cycle of research, after signing the memorandum of agreement, the $\mathrm{HO}$ arranged for more than 20 interviews of 40-60 minutes within four days of a visit between the researchers and the heads of logistics, warehousing, procurement, research and development, and water and sanitation. The interviews were conducted using open-ended questions. The interview protocol was developed based on the problem statement and research question. The interviewees were asked about their responsibilities, how they thought their responsibilities connected to environmental sustainability, what were the major sustainability concerns, and potential solutions to address those concerns. All the interviews were audio-recorded to be coded later. Another visit was planned to a refugee camp in Kenya to observe end-of-life management of packaging in situ. In addition to the qualitative data gathered from the visits, the researchers were granted remote access to 
several organisational databases through which quantitative data about the HO's operations were gathered. The practitioner team contributed to data gathering by granting access and helping the researchers in sensemaking of organizational data whenever there were ambiguities. While data collection was a continuous process throughout the partnership, initial data collection from different sources took about two months.

In the second cycle, two joint CRM meetings were held in the headquarters; more interviews were conducted with the HO staff. Following perceived success in the first cycle, the $\mathrm{HO}$ expanded remote access to the researchers of their databases.

\section{Practitioner orientation}

Based on the collected data from the headquarters and the field, the researchers conducted a preliminary environmental analysis of the HO's packaging. The assessment included all the environmental impact categories from last-mile distribution to end-of-life. The practitioner team assisted the researchers by answering queries and providing further data on the fate of packaging. The research team presented the results of environmental impact assessment during an online meeting.

From the second cycle, based on the collected data from suppliers and the field, the researchers developed a cradle-to-grave environmental analysis for packaging starting from suppliers to disposal.

\section{Collaborative data analysis}

In the first cycle a joint meeting was held at the headquarters where the research team presented the problem, a synthesis of the collected data, and the methodology used to develop green practices, involving a literature review, setting of benchmarks, followed by contextualization of practices for the collected data. Specifically, humanitarian factors that might impact on implementation of green practices were jointly analysed. The joint discussion led to a shared understanding of the issue before proceeding to co-develop action steps (Shani, Tenkasi et al. 2018).

In the second cycle greening solutions were proposed to redesign the packaging. These were sent to the practitioner team to elicit feedback prior to another joint meeting. The practitioner team sent the solutions to internal quality control advisors and also suppliers. In this cycle the CRM team focused on collaborative sense-making about any actions that appeared to have been less successful in the first cycle. 


\section{Joint planning for action}

Based on feedback from the first cycle, it was jointly decided that the researchers focus on the design of packaging for food ingredients since changing medical products' packaging was unlikely due to medical regulations and high standardization.

In the CRM process, the researcher and practitioner teams engaged in conversational inquiry to generate a shared understanding and planning for action (Canterino et al. 2016). This involved discussing possible scenarios for action, assigning responsibilities for implementation, and defining details of the action plan (Shani et al. 2018). The action plan focused on incinerating food packaging waste local to the refugee camp.

\section{Implementation and evaluation}

Instructions were communicated to local staff and an incinerator was installed near the refugee camp. Implementing the action plan in the field is the most important step that influences not only the practical outcomes, but also the impact of using CRM (Shani et al. 2018).

\section{Monitoring}

Evaluating the quality of a CRM study involves a continuous effort by researchers to achieve a balance between scholarly rigour, reflectiveness, and relevance (Canterino et al. 2016). In this project the researchers considered scholarly rigour from the initial stages of research design. During the first cycle, the interviews were designed based on the research question while they captured the peculiarities of the humanitarian organization's operations. Since conducting CRM in organisations requires distinct quality criteria (Coghlan and Shani, 2014), rigour, reflectiveness and relevance were assessed during and after each cycle, the results of which are reported in findings below.

\subsection{Findings}

\section{Forming the team}

For the research to be successful, it was crucial that the practitioner partners were committed to intense collaboration from the outset. Of the three HOs targeted, only one expressed this commitment. Choice of organisational partner was critical prior to 
attempting to commence collaborative research. Because academic access to corporate elites to conduct research is challenging (Welch et al, 2002), it is an unusual situation for academics to have to choose between partner organisations, but it is essential in collaborative research. This choice was a two-way process with the practitioner partners examining the suitability and credibility of the proposed academic partners. This resulted in confidence forming prior to the commencement of research. This confidence building extending into the field team: because field staff were recruited in the first cycle of research, there was less resistance by the time the second cycle was conducted. Early involvement of practitioners who may be involved later in implementation has been found to be an important element of collaborative research in other settings (see, for example, Suarez-Balcazar et al, 2005).

\section{Understanding the problem and context}

Conflicting objectives between urgent response to save lives and engaging in environmental sustainability were a source of ongoing tension in the research, as illuminated in interviews.

"Some people here still argue that our job is saving lives and environmental sustainability is not our mission." Logistics manager of the HO.

The cyclical approach of CRM requires the review of the outcomes and the lessons learnt from the previous cycle (Shani et al. 2018). The implemented actions and their outcomes from cycle 1 were reviewed at the beginning of cycle 2 to revisit the shared understanding of the problem and context. The practitioner team reconfirmed that packaging waste was a pressing concern:

"We are facing [a] large amount of packaging in the field mostly made from plastic. I think it is a great starting point." Logistics coordinator of Africa.

\section{Data Collection}

Learnings from the first cycle revealed that significant volumes of packaging waste could be avoided through better packaging design. In the second cycle, therefore, the attention of the CRM team turned towards collecting data from suppliers. Three major suppliers of food ingredients and medical products were selected by the practitioner team and connected to the research team. The researchers collected data from the selected suppliers using a questionnaire about technical specifications of the packaging used, followed by 
three one-hour interviews with production managers about packaging design, quality, and waste during production.

\section{Practitioner orientation}

In a joint meeting with the practitioner partners, the research team presented a summary of action steps from the first cycle, evaluation of outcomes, and proposed the project should enhance green practices.

\section{Collaborative data analysis}

In the analysis, the practitioner team dismissed some of the proposals because they perceived them as inappropriate to the HO's supply chain. For example, the proposal to export packaging waste to a neighbouring country with a recycling facility was rejected. While this practice is used in commercial supply chains (see, for example, Rucevska et al, 2017), it is more difficult to do in humanitarian supply chains due to tensions at the borders, lack of support from authorities, and poor import/export legislation.

"Even within a country, we have problems moving waste from remote areas to the capital for recycling. Let alone transporting waste across the borders. The governments would not allow to import packaging waste" Logistics coordinator of Africa.

Other impeding factors were poor recycling facilities in developing countries and regions impacted by a crisis, lack of robust national regulations, limited beneficiaries' awareness of proper disposal methods, and the HO's negligence to design reverse logistics properly. Additionally, expired products were a major problem as they required separation of the content (e.g. food or medicine) from the packaging prior to recycling.

Comparing analysis with the benchmarks set for packaging waste in the project revealed that many refugees receiving food products were far from waste collection points in the camp; the practitioner team were not previously aware of this problem. The existing waste collection points and bins were designed by the HO several years previous when the population of refugees in the camp was far less. Based on these new insights, the CRM team jointly assessed requirements for additional waste collection points and optimal locations for them. 
As for packaging design, analysis of the questionnaires and interviews with suppliers revealed room for improving sustainability of packaging through reducing use of plastic or substituting with cost efficient greener alternatives. While agreeing with the proposed solutions, the practitioner team argued that such changes should not be expected overnight but could be developed through long-term collaboration with suppliers.

\section{Joint planning for action}

The action plan contained three main steps tackling disposal of waste. First, the CRM team proposed to raise beneficiaries' (refugees receiving food) awareness about proper waste disposal at the time of food distribution. The plan proposed training field staff to show beneficiaries how to dispose of packaging after consumption and where their closest waste collection point was. The second action proposed providing financial incentives to people collecting packaging waste; this engaged the local populations in the camp, providing social and economic benefit in additional to environmental gains. The third action focused on disposing of expired products through incineration and landfill, taking care to avoid leaching of organic waste into underground water through use of cement where water tables were high. This third action resulted in the formation of disposal instructions for packaging and expired products with non-hazardous material. The HO management team agreed to assign budget to buy a mobile high-temperature incinerator to implement this action point.

Upstream in the supply chain, three actions were planned with respect to suppliers. First, suppliers were asked to include visual presentation on the packaging of how to dispose of it after consumption. Second, compliance over the coming years with Forest Stewardship Council certification was requested of suppliers. This focused on recycling cardboard materials for reuse as shipping boxes, eliminating plastic from gross boxes and carton liners, and encouraging use of biodegradable packaging. Third, take-back clauses were added to new contracts with suppliers.

\section{Implementation and evaluation}

Downstream in the supply chain in the refugee camp, the number of communal storage bins for domestic waste was increased. Efforts to encourage beneficiaries' awareness of waste disposal were intensified through adding education workshops and targeting instructions on waste disposal to heads of families. However, in the refugee camp in Kenya these actions had limited effect. Efforts on reverse logistics planning were greatly 
improved, minimizing open-air incineration and increasing transport of waste to the newly installed incinerator, as highlighted in the dialogue below:

"Do you think it will have less environmental impact than burning them locally? Because it adds a shipment." HO Logistics manager

"Yes, sending by a truck emanates way less emissions than burning large quantities of packaging in open air" Researcher

"That's interesting because to me, I would have been clueless, but for you it's easy 'cause you know it has higher impact with the low temperature burning. Do we have some sort of evidence or graph on that?" HO Logistics manager "Yes, that is in the environmental analysis report." Researcher "Super! I think we should include that in our guidelines to the field." Logistics manager This dialogue illustrates how co-inquiry evolves in the context of application through the engagement of CRM members (Coghlan and Shani 2014) and how researchers can play a role in presenting academic knowledge to practitioners to bring about change in organizations (Shani, Tenkasi et al. 2018).

Local staff were already dealing with large amounts of expired items (e.g. therapeutic food) due to the influx of unsolicited international donations following a past crisis in the region. Before incineration, outer-box packaging was removed since it was made of cardboard which could be easily recycled or reused. The instructions mandated that at least two permanent, non-volunteer staff should accompany and supervise the disposal process to mitigate risk of pilferage. Despite increased costs for transportation and incineration, the exercise was perceived as successful.

The financial incentive for waste packaging collection was successful for polypropylene packaging but less so for other types of packaging that tended to be more contaminated by food leftovers and mud and had to be cleaned before weighing and subsequent payment.

The growing mounds of food packaging waste and emergency supplies were palpable in the camp posing health concerns; septic tanks and pit latrines became blocked and malaria 
and yellow fever carrying mosquitoes bred more rapidly. During the four months implementation revisions and tweaking were required, but broadly the implementation phase were viewed as successful.

Implementation was rolled out to more delegations in the south and east of Africa. Gradually visible results in reducing packaging waste were observed. However, reluctance was experienced, reemphasising the importance of early involvement of field staff in the co-creation of action steps.

Suppliers made good progress. All packaging was revised to include instructions on proper disposal. Reduction of plastic and use of greener substitutes was ongoing but being achieved gradually.

\section{Monitoring}

Monitoring was performed through examining rigour, relevance and reflectiveness, as presented in Table 4.

\section{Please insert Table 4. Rigour, relevance, and reflectiveness criteria in the present case study}

\section{Discussion}

The inclusive nature of collaborative research impacted suppliers, affected populations, local humanitarian workers, the international humanitarian organisation and the research team. During the research process, trust has increased amongst members of the collaborative research team. As a result better coordination and decrease of adverse effects of uncertainty was observed, improving management across the stakeholders in this complex network of actors.

In contrast to propositions of previous studies (c.f. Sabri, 2018), as depicted in table 5, there was no evidence of adverse impact of the changes on donations or post-disaster management. However, these are more influenced by the crisis itself, rather than the logistics response to the crisis. Overall the improvement of waste management processes at the affected location and improvements to the packaging design and process at suppliers were substantially improved. Awareness of the affected population had noticeably increased leading to improved social inclusion in the efforts. Implementation 
of the collaborative research methods process, contextualised for humanitarian supply chains, was viewed as successful, in the main.

However, several challenges of using collaborative research methodologies were encountered in this research. First, forming the team took substantial time and effort to engage a humanitarian organisation and negotiate the nature of that engagement with them. As this research project was not granted funding, only access to rich data, the costs of these efforts were borne by the researchers and their universities.

\section{Please insert Table 5. Expected versus actual implications of applying CRM in humanitarian supply chains}

Trust is a cornerstone in successful collaborative research. One of the HOs approached was interested in the research problem but was unwilling to collaborate more than be interviewed and engage in observational research. This may be because of lack of trust in the researchers or in the methods and shared responsibilities of collaborative research. Trust was crucial to project continuation (here, to the second cycle of research) and future research. Post this research the HO actively pursued further discussions for future collaborative research.

Tweaks and changes to the collaborative research methods process used were made. In the initiation phase of this research project, to manage the stakeholder's expectations, the research team and $\mathrm{HO}$ signed a memorandum of agreement, so as to have a clear explanation of the scope and aim of the research. Furthermore, to avoid any conflicts, this memorandum identified the CRM team members, their roles, and the range of their intervention during the different phases of the research project. The memorandum provided clear identification of the deliverables of the research team, and the expected time horizon for the collaboration. Adding to the process a requirement for a detailed, signed memorandum was perceived to be vital to the success of using collaborative research methods.

In the data collection and data analysis phases, there was no manipulation by the management team as their genuine intent was to solve the issue from its root causes; as such, they provided the researchers with full access to high-quality data and facilitated their field visits. Explicit mention in these phases that data access, collection and analysis should not be manipulated by the practitioner partners sends a clear signal of the need for openness in collaborative research. 
Implementation challenges that impacted on the collaborative research included:

- unpredictable contingencies that impact on action plans, such as budget restrictions

- frequent movement of employees in humanitarian organisations, making it difficult to maintain long-term collaboration

- being prone to procrastination by practitioner partners until feasible results are visible, making the collaborative research very time and resource consuming

The monitoring phase was performed by an internal member of the research team, rather than triangulation with an observer researcher as proposed in the collaborative research methods process. This project suffered from lack of funding so persuading a third party researcher to engage without funding proved unsuccessful. Triangulation of methodologies and engagement of external interdisciplinary researchers is very challenging in practice; planning more in advance for this might help, but there is no simple solution to how to conduct collaborative research in highly resource constrained settings, such as humanitarian supply chains.

Whilst this research used academic-practitioner collaboration in the collaborative research methods process, unexpectedly during application of the methods, affected population engagement became a feature of the research (through incentivising collection or waste and providing education to improve waste disposal). This was not anticipated at the outset of the research and highlights the need for flexibility in use of collaborative research methods. The act of engagement and collaboration gave rise to these changes, emphasising the challenges of planning and controlling collaborative research projects. Another important observation was a noticeable resistance of the humanitarian field staff to change. In this research the second cycle was conducted more easily in the refugee camp where the field staff were already involved in the first cycle, as compared to implementation in other countries where field staff had had no prior involvement.

Collaborative research is much more time-consuming than conventional research approaches. Case studies may be conducted in a few months in non-engaged scholarship, but a CRM-based case study sometimes requires years to build trust, devise action steps, complete cycles of implementation, and observe and reflect on the changes.

The in-depth nature of engaged scholarship in a single case study over time in a deep, extended collaboration, is appreciated for the richness of research findings (Dyer et al, 1991) but developing theoretical constructs leading to theory building may require reflectiveness across a number of such cases (Eisenhardt, 1991). As such it is 
recommended as more appropriate to early stage exploratory research or late stage theory testing (Yin, 2017). However, single case study research is still plagued with criticisms of idiosyncratic nature of the sample of one (Stuart et al, 2002).

A particular challenge of collaborative research in humanitarian supply chains lies in the nature of humanitarian aid being reliant on donations. Disclosure of action research results and reporting any shortcomings of practitioners in publications can impact on the social image of the practitioner organisations. The temptation of $\mathrm{HO}$ managers to present a positive light on their operations might be strong, though CRM studies are likely to expose and try to improve failings.

\subsection{Summary of refinements to the collaborative methods process}

In the first phase of understanding the context and forming the research team, we suggest signing a memorandum of understanding that clearly defines the role of each actor in the team and a potential time-line for the research project. This helps in expectations management of each party (i.e. the researchers and practitioners) and better management of the research cycles.

To overcome the implications of frequent rotation of humanitarian officers in the field, the practitioner orientation phase should include a step where researchers make sure there is a mechanism for internal knowledge sharing to orient the substitute practitioners and align them rapidly with the objectives of the collaborative research project. Electronic communication technologies such as webinars or recorded online trainings can be of help here. Moreover, researchers should keep track of all the collected data through recording interviews and reflective sessions, taking photos (e.g. from plastic waste in the refugee camp in the presented case), and other measures of data storage. This is important especially due to volatility and fast-changing nature of the humanitarian logistics context. In the 'joint planning for action' phase, it is suggested to consider it as a composite of two main sub-steps. First, different scenarios of collaboration under different possible situations that might arise in future should be developed. This pertains to the uncertainty within the humanitarian context and differentiates application of CRM-based methods in humanitarian logistics from commercial logistics. Second, unlike commercial logistics settings, it is not a dyad of practitioner-researcher collaboration that results in the cocreation of actionable knowledge, but the "triad" of humanitarian organisations managers-field staff-researcher and even the "tetrad" of humanitarian organisation 
managers-field staff-affected population-researcher. If the actions are planned in the absence of, or without communicating with field staff, there are high chances of failure in implementation because some peculiarities of the field may not be seen and field staff might be reluctant because they were not involved earlier.

\section{Conclusions}

\subsection{Contribution to theory}

The central thesis of this article is to challenge the prevalent understanding of knowledge generation in the humanitarian supply chain domain, previously based on use of a limited range of research methodologies (Kunz and Reiner, 2012; Naslund, 2002; Naslund et al 2010). Collaborative methodologies have been shown here to be perceived as appropriate to humanitarian supply chain research (Sohn, 2018; Sabri, 2018; Prasad et al, 2017) but, to date, only generic collaborative research methodology processes have existed (Coughlan and Coghlan, 2002; Nashlund et al, 2010; Sabri, 2018). This article contributes a collaborative research methods process, contextualised for research in humanitarian supply chains through integrating existing generic processes with findings from collaborative research conducted in humanitarian settings. The resulting 8 phase process was tested and refined in an exploratory in-depth case study. The positive impact of the research on humanitarian logistics and affected populations supports the efficacy of the process. The process therefore contributes to supply chain management theory, in testing the use of collaborative research methods in supply chains, but more specifically to humanitarian logistics theory through provision of a unique process, contextualised to that setting.

\subsection{Contribution to practice}

Humanitarian logistics managers within the research learnt from the collaborative research process and outcomes, making substantial logistics improvements to the environmental sustainability of food packaging design and disposal. Collaboration across the various stakeholders relating to the environmental detriment caused by food packaging improved as a result of using collaborative research methods; this collaboration led to positive, practical impact. Supplier development improved as a result of the joint initiative to redesign packaging and its reuse in the supply chain. This 
exploratory research can be built on in the humanitarian logistics field through further application of this new collaborative research methods process, through increasing collaboration with academia to solve problems in the field. Greater understanding and awareness of the power of academic-practice collaboration to help solve the many wicked problems faced in humanitarian settings should provide new avenues for supporting improvement initiatives. Highlighting attention on the humanitarian logistics aspects of crises, and the potentially powerful role suppliers and logistics can play in preventing spill-over burdens of humanitarian aid to local societies (e.g. increased risk of malaria, yellow fever and cholera) and environments (e.g. polluting local water supplies) encourages action beyond the immediate crisis to consider longer term implications.

Engagement of locally affected populations (in what became a tetradic, or 4 party, collaboration of academics, humanitarian organisation managers, local field staff and affected populations) impacted on their lives through reduction of hazards affecting health, and through economic and social inclusion. Their awareness of the importance of sustainable development relating to donated food improved; however in some of the African nations where this was rolled out, this awareness did not lead to substantially reducing problems of waste disposal.

It is likely that the long term, collaborative nature of this research and the implementation of the collaborative research methods process, is more appropriate to post-crisis logistics situations and long term crises, such as tackling poverty or migrants, but less so for rapid response situations.

\subsection{Limitations and future research}

A single, exploratory case study doesn't provide statistical generalisability of the findings. However, the findings provide analytical generalisability and transferability to relevant domains. Further application in other aspects of humanitarian logistics of the collaborative research methods process provided here would enable more general understanding of the appropriateness of collaborative research methods. However, the resource intensity of using collaborative research methods in environments constantly in flux, subject to great uncertainty, as are those in humanitarian settings, combined with lack of research funding, prohibits substantial application. High and rapid staff turnover in the field, challenges of engaging large numbers and variety of stakeholders and 
uncertainty of convergence of donations all exacerbate complexity and resource demands on humanitarian logistics researchers. The nature of collaborative research entails higher commitment from both researchers and practitioners. Not insignificant are the risks to researchers operating in difficult conditions with threats to their safety and security. It is unsurprising, therefore, that methods used in humanitarian logistics research have been more 'hands off' and less collaborative.

\section{References}

Abrahams, D. (2014). "The barriers to environmental sustainability in post-disaster settings: a case study of transitional shelter implementation in Haiti." Disasters, 38, S25-S49.

Ben-Tal, A., Do Chung, B., Mandala, S. R., and Yao, T. (2011). "Robust optimization for emergency logistics planning: Risk mitigation in humanitarian relief supply chains." Transportation research part B: methodological, 45(8): 1177-1189.

Brydon-Miller, M., Greenwood, D., and Maguire, P. (2003). Why action research? Action research, 1(1), 9-28.

Canterino, F., Shani, A. B. R., Coghlan, D., and Brunelli, M. S. (2016). Collaborative Management Research as a Modality of Action Research Learning from a MergerBased Study. The Journal of Applied Behavioral Science, 52(2) 157-186.

Chandes, J., \& Paché, G. (2010). "Investigating humanitarian logistics issues: from operations management to strategic action." Journal of Manufacturing Technology Management, 21(3), 320-340.

Chandes, J., and Paché, G. (2010). "Investigating humanitarian logistics issues: from operations management to strategic action." Journal of Manufacturing Technology Management, 21(3), 320-340.

Chang, Y. J., Liao, R. H., Wang, T. Y., \& Chang, Y. S. (2010). “Action research as a bridge between two worlds: helping the NGOs and humanitarian agencies adapt technology to their needs." Systemic Practice and Action Research, 23(3), 191-202.

Chang, Y. J., Liao, R. H., Wang, T. Y., and Chang, Y. S. (2010). "Action research as a bridge between two worlds: helping the NGOs and humanitarian agencies adapt technology to their needs." Systemic Practice and Action Research, Vol. 23 No. 3, pp. 191-202.

Coghlan, D. (2011). Action Research: Exploring Perspectives on a Philosophy of Practical Knowing. The Academy of Management Annals, 5, 53-87.

Coghlan, D. and A. B. Shani (2014). "Creating Action Research Quality in Organization Development: Rigorous, Reflective and Relevant."Systemic Practice and Action Research, Vol 27, No.6: pp.523-536.

Coghlan, D. and A. B. Shani (2014). Creating Action Research Quality in Organization Development: Rigorous, Reflective and Relevant. Systemic Practice and Action Research, 27, 523-536.

Coughlan, P., and Coghlan, D. (2002). Action research for operations management. International Journal of Operations and Production Management, 22(2), 220-240.

Cravioto, A., Lanata, C., Lantagne, D., and Nair, G. (2011). Final report of the independent panel of experts on the cholera outbreak in Haiti. Retrieved from http://www.lessonsfromhaiti.org/download/Report Center/UN-cholera-reportfinal.pdf, September 2018. 
Dyer Jr, W. G., \& Wilkins, A. L. (1991). Better stories, not better constructs, to generate better theory: A rejoinder to Eisenhardt. Academy of management review, 16(3), 613619.

Eisenhardt, K. M. (1991). Better stories and better constructs: The case for rigor and comparative logic. Academy of Management review, 16(3), 620-627.

Ellström, P.-E. (2007). Knowledge Creation Through Interactive Research: A Learning Perspective, In HHS-07 Conference, Jönköping University, May (pp. 8-11).

Eng-Larsson, F. and D. Vega (2011). "Green Logistics in Temporary Organizations: A Paradox? Learnings from the Humanitarian Context." Supply Chain Forum: An International Journal, Vol.12, No.2, pp.128-139.

Gammelgaard, B. (2004), "Schools in Logistics Research? A Methodology Framework for Analysis of the Discipline", International Journal of Physical Distribution \& Logistics Management, Vol. 34, No. 6, pp. 479-491

Gatignon, A., et al. (2010). "The Yogyakarta earthquake: Humanitarian relief through IFRC's decentralized supply chain." International Journal of Production Economics 126(1): 102-110.

Gray, J. M. (2004). Evidence based policy making, British Medical Journal Publishing Group.

Haavisto, I. and G. Kovács (2014). Perspectives on sustainability in humanitarian supply chains. Disaster Prevention and Management: An International Journal, 23, 610-631.

Haavisto, I. and J. Goentzel (2015). Measuring humanitarian supply chain performance in a multi-goal context. Journal of Humanitarian Logistics and Supply Chain Management, 5, 300-324.

Hamet, J., \& Michel, S. (2018). Rigor, relevance, and the knowledge "market". European Business Review, 30(2), 183-201.

Jahre, M., Dumoulin, L., Greenhalgh, L. B., Hudspeth, C., Limlim, P., \& Spindler, A. (2012). "Improving health in developing countries: reducing complexity of drug supply chains." Journal of Humanitarian Logistics and Supply Chain Management, Vol. 2 No. 1, pp. 54-84.

Jahre, M., Ergun, O., \& Goentzel, J. (2015). One Size Fits All? Using Standard Global Tools in Humanitarian Logistics. Procedia Engineering, 107, 18-26.

Kieser, A., \& Leiner, L., (2012), Collaborate with Practitioners: But Beware of Collaborative Research, Journal of Management Inquiry, 21 (1), 14-28.

Kovács, G. and Moshtari, M. (2018), "A roadmap for higher research quality in humanitarian operations: A methodological perspective." European Journal of Operational Research.

Kovács, G., and Spens, K. M. (2007). Humanitarian logistics in disaster relief operations. International Journal of Physical Distribution \& Logistics Management, 37(2), 99114.

Kovács, G., and Spens, K. M. (2011). Trends and developments in humanitarian logistics -a gap analysis. International Journal of Physical Distribution \& Logistics Management, 4l(1), 32-45.

Kovner, A. R. and T. G. Rundall (2006). Evidence-based management reconsidered. Frontiers of health services management, 22(3): 3.

Kunz, N. and S. Gold (2017). "Sustainable humanitarian supply chain management exploring new theory." International Journal of Logistics Research and Applications 20(2): 85-104.

Kunz, N., \& Reiner, G. (2012). A meta-analysis of humanitarian logistics research. Journal of Humanitarian Logistics and Supply Chain Management, 2(2), 116-147. 
Leiras, A., de Brito Jr, I., Queiroz Peres, E., Rejane Bertazzo, T., \& Tsugunobu Yoshida Yoshizaki, H. (2014). Literature review of humanitarian logistics research: trends and challenges. Journal of Humanitarian Logistics and Supply Chain Management, 4(1), 95-130.

Lykes, M. B. (2013). "Participatory and action research as a transformative praxis: Responding to humanitarian crises from the margins." American Psychologist, 68(8), 774.

Lykes, M. B., \& Scheib, H. (2016). "Visual methodologies and participatory action research: Performing women's community-based health promotion in post-Katrina New Orleans." Global public health, 11(5-6), 742-761.

MacLean, D., Macintosh, R. \& Grant, S. (2002), Mode 2 Management Research, British Journal of Management, 13(3), 189-207.

Manikas, A. S., Kroes, J. R., \& Gattiker, T. F. (2017). Leveraging Academic Partnerships to Improve Logistics at Nonprofit Organizations. Nonprofit Management and Leadership, 27(3), 435-444.

McManners, P. (2016). The action research case study approach: A methodology for complex challenges such as sustainability in aviation. Action Research, 14(2) 201216.

Näslund, D. (2002). Logistics needs qualitative research-especially action research. International Journal of Physical Distribution \& Logistics Management, 32(5), 32133

Näslund, D., Kale, R., \& Paulraj, A. (2010). Action research in supply chain management - a framework for relevant and rigorous research. Journal of Business Logistics, 31(2), 331-355.

Nelson, B. D., Getchell, M., Rosborough, S., Atwine, B., Okeyo, E., Wall, E., \& Greenough, P. G. (2010). "A participatory approach to assessing refugee perceptions of health services." World health \& population, 11(4), 13-22.

Pasmore, W.A. et al. (2008). The promise of of collaborative management research. In Shani, A.B. (Rami), Mohrman, S., Pasmore, W.A., Stymne, B., \& Adler, N. (Eds.), Handbook of Collaborative Management Research, Thousand Oaks, CA: SAGE, pp. 7-31.

Pedraza-Martinez, A. J., Stapleton, O., \& Van Wassenhove, L. N. (2013). "On the use of evidence in humanitarian logistics research.” Disasters, 37, S51-S67.

Pfeffer, J. and R. I. Sutton (2006). "Evidence-based management." Harvard business review, 84(1): 62 .

Prasad, S., Sundarraj, R. P., Tata, J., \& Altay, N. (2017). "Action-research-based optimisation model for health care behaviour change in rural India." International Journal of Production Research, 1-19.

Prasad, S., Sundarraj, R. P., Tata, J., \& Altay, N. (2017). "Action-research-based optimisation model for health care behaviour change in rural India." International Journal of Production Research, 1-19.

Refstie, H., \& Brun, C. (2011). "Towards transformative participation: Collaborative research with 'Urban IDPs' in Uganda.” Journal of Refugee Studies, 25(2), 239-256.

Refstie, H., \& Brun, C. (2011). "Towards transformative participation: Collaborative research with 'Urban IDPs' in Uganda." Journal of Refugee Studies, Vol. 25 No. 2, pp. 239-256.

Regattieri, A., et al. (2018). "Innovative Solutions for Reusing Packaging Waste Materials in Humanitarian Logistics." Sustainability 10(5): 1587.

Robbins, S. De CENZO D (2008), Fundamentals of Management, Upper Saddle River, NJ: Prentice Hall. 
Rucevska, I., Nellemann, C., Isarin, N., Yang, W., Liu, N., Yu, K., ... \& Bisschop, L. (2017). Waste Crime-Waste Risks: Gaps in Meeting the Global Waste Challenge. A UNEP Rapid Response Assessment.

Rutta, E., Williams, H., Mwansasu, A., Mung'ong'o, F., Burke, H., Gongo, R., ... \& Qassim, M. (2005). "Refugee perceptions of the quality of healthcare: findings from a participatory assessment in Ngara, Tanzania." Disasters, 29(4), 291-309.

Sabri Y. (2018) Deploying Collaborative Management Research Approaches in Humanitarian Supply Chains: An Overview and Research Agenda. In: Kovács G., Spens K., Moshtari M. (eds) The Palgrave Handbook of Humanitarian Logistics and Supply Chain Management. Palgrave Macmillan, London

Sandvik, K. B., \& Lemaitre, J. (2013). "Internally displaced women as knowledge producers and users in humanitarian action: the view from Colombia." Disasters, Vol. 37, S36-S50.

Sandvik, K. B., \& Lemaitre, J. (2013). "Internally displaced women as knowledge producers and users in humanitarian action: the view from Colombia." Disasters, 37, S36-S50.

Sarkis, J., Spens, K. M. \& Kovács, G. (2012). A Study of Barriers to Greening the Relief Supply Chain. In: Spens, K. M. \& Kovács, G. (eds.) Relief Supply Chain Management for Disasters: Humanitarian Aid and Emergency Logistics. Hershey PA, United States of America: IGI Global: 196-207.

Schein, Edgar H., (2006) Clinical Inquiry/Research, in Reason, P. \& Bradbury, H., (Eds.), Handbook of Action Research, Paperback Edition. Sage. London.

Shani, A. B. R., Tenkasi, R. R. V. and Alexander, B. N. (2018). Knowledge and Practice: A Historical Perspective on Collaborative Management Research. In: Bartunek, J. M. and McKenzie, J. (eds.) Academic-Practitioner Relationships: Developments, Complexities and Opportunities. Routledge.

Shani, A.B. (Rami), Coghlan, D., and Cirella, S. (2012). Collaborative management research and action research: More than meets the eye? International Journal of Action Research. 8 (1), 46-67.

Shani, A.B. (Rami), David, A., and Willson, C., (2004), Collaborative research: Alternative roadmaps. In Adler, N., Shani, A.B. (Rami) and Styhre, A., (Eds.) Collaborative Research in Organizations: Foundations for Learning, Change and Theoretical Development, Thousand Oaks, CA: SAGE, pp. 83-100.

Sohn, M. (2018). So Much of Research Is Context: Fieldwork Experience in Humanitarian Logistics. in Kovács, G., Spens, K. M., Moshtari, M. (eds). In The Palgrave Handbook of Humanitarian Logistics and Supply Chain Management (pp. 149-177). Palgrave Macmillan, London.

Sohrabpour, V., Hellström, D. and Jahre, M. (2012). Packaging in developing countries: identifying supply chain needs. Journal of Humanitarian Logistics and Supply Chain Management, Vol. 2 No. 2, 183-205.

Stuart, I., McCutcheon, D., Handfield, R., McLachlin, R., \& Samson, D. (2002). Effective case research in operations management: a process perspective. Journal of operations management, 20(5), 419-433.

Suarez-Balcazar, Y., Harper, G. W., \& Lewis, R. (2005). An interactive and contextual model of community-university collaborations for research and action. Health Education \& Behavior, 32(1), 84-101.

Sundel, M. (1999). "A social systems approach to improve mental health collaboration and ethnic relations in Cyprus." Systems Research and Behavioral Science: The Official Journal of the International Federation for Systems Research, 16(5), 463-472. 
Svensson, L., Ellström, P.-E., and Brulin, G. (2007). "Introduction - in interactive research." International Journal of Action Research, 3(3), 233-249)

Tanabe, M., Nagujjah, Y., Rimal, N., Bukania, F., \& Krause, S. (2015). "Intersecting sexual and reproductive health and disability in humanitarian settings: risks, needs, and capacities of refugees with disabilities in Kenya, Nepal, and Uganda." Sexuality and disability, 33(4), 411-427.

Tanabe, M., Pearce, E., \& Krause, S. K. (2018). "Nothing about us, without us": Conducting participatory action research among and with persons with disabilities in humanitarian settings." Action Research, 16(3), 280-298.

Tomasini, R. M., and Van Wassenhove, L. N. (2009). From preparedness to partnerships: case study research on humanitarian logistics. International Transactions in Operational Research, 16(5), 549-559.

Touboulic, A., \& Walker, H. (2016). A relational, transformative and engaged approach to sustainable supply chain management: The potential of action research. Human Relations, 69(2) 301-343.

Van de Ven, A. H., and Johnson, P. E. (2006). Knowledge for theory and practice. Academy of management review, 31(4), 802-821.

van den Muijsenbergh, M., Teunissen, E., van Weel-Baumgarten, E., \& van Weel, C. (2016). "Giving voice to the voiceless: how to involve vulnerable migrants in healthcare research.” British Journal of General Practice, June 2016, 284-285.

van den Muijsenbergh, M., Teunissen, E., van Weel-Baumgarten, E., and van Weel, C. (2016). "Giving voice to the voiceless: how to involve vulnerable migrants in healthcare research.” British Journal of General Practice, June 2016, 284-285.

Van Kempen, E. A., Spiliotopoulou, E., Stojanovski, G. and De Leeuw, S. 2017. Using life cycle sustainability assessment to trade off sourcing strategies for humanitarian relief items. The International Journal of Life Cycle Assessment, 22(11), 1718-1730.

Van Wassenhove, L. N. (2006). Humanitarian logistics: supply chain management in high gear. Journal of the Operational Research Society, 57(5), 475-489

Welch, C., Marschan-Piekkari, R., Penttinen, H., \& Tahvanainen, M. (2002). Corporate elites as informants in qualitative international business research. International Business Review, 11(5), 611-628.

Yin, R. K. (2017). Case study research and applications: Design and methods. Sage publications. 